\title{
Study on the Effects of Gloss Type on Chinese EFL Learners' Incidental Vocabulary Acquisition* $^{*}$
}

\author{
Xiaoli Gan \\ School of Foreign Languages, Sichuan University of Arts and Science, Dazhou Sichuan 635000, China

\begin{abstract}
Gloss is a common practice in reading materials. This study aims to explore the effects of gloss type on Chinese EFL learners' English incidental vocabulary acquisition through reading. The experimental results indicate that: (1) multiple-choice glosses outperformed single glosses in incidental vocabulary gain and retention during reading; (2) compared with single glosses, multi-choice glosses were more conductive to vocabulary production.
\end{abstract}

Index Terms - incidental vocabulary acquisition, glossing, gloss type

\section{INTRODUCTION}

Since learning a second language involves the learning of large number of words, EFL teachers and researchers have shown a keen interest in finding out how words can be learned most efficiently (Hulstijn, 1996; Laufer, 2001; Mondria, 2003). In the past decades numerous studies have been conducted to investigate the effects of different tasks on vocabulary acquisition (Watanabe, 1997; Nagata, 1999; Rott, 2005; Makoto, 2006).

The term incidental vocabulary acquisition, which was first put forward in the feild of psychology, is subject to different interpretations. Huckin and Coady $(1999$, p.182) stated that incidental vocabulary learning is "a by product, not the target, of the main cognitive activity, reading". They defined incidental vocabulary learning according to learners' purpose held during the process of reading, and their view implies that incidental vocabulary learning is the result of uncontrolled learning.

Glossing in reading materials for unknown English words is a very common practice in China, and it is mainly used to aid text comprehension and serve as a way of facilitating incidental vocabulary acquisition through reading as well. Frequently it substitutes for the traditional dictionary with which learners have to switch focus from the texts to dictionaries with the consequent waste of time and effort. That's to say, the practice of glossing in reading materials can compensate for a shortage of contextual information and hence contribute to EFL learners' vocabulary development.

\section{A. The Concept of Incidental Vocabulary Acquisition}

Foreign language learners' mastery of vocabulary, to a great extent, determines their language proficiency. That's why vocabulary is believed to be the essence of a language. An important question in language learning is how to optimize the gain of new words. In the past decades numerous studies have illustrated that vocabulary can be acquired through reading.

Nation (1990, p.2) claimed that "In indirect vocabulary learning the learners' attention is focused on some other feature, usually the message that is conveyed by a speaker or writer". And such indirect vocabulary learning is called incidental vocabulary learning. Nation interprets the term from the perspective of learners' attention. It's regarded that incidental learning requires attention to be placed on meaning but allows peripherial attention to be directed at form. Most researchers agree that EFL learners would have to acquire their first few thousand words intentionally since they lack enough proficiency in the target language to just "pick up" the meaning of the new words. However, most vocabulary is acquired incidentally later on in the learning process since it occurs as a result of other activities which are related to reading.

In addition, Laufer and Hulstijn (2001, p.10) stated that "In experiments investigating incidental vocabulary learning, the learners are typically required to perform a task involving the processing of some information without being told in advance that they will be tested afterwards on their recall of that information". According to them, the absence of notification of a task in advance induces incidental vocabulary learning. Hulstijn (2003) restated that incidental learning occurs, as participants in a psychological experiment are not informed of a test after the experiment beforehand. Both Laufer and Hulstijin emphasize that a lack of an idea of subsequent tasks plays a critical role in identifying incidental vocabulary acquisition.

To sum up, the different interpretations of incidental vocabulary acquisition listed above imply that incidental

\footnotetext{
* This paper is sponsored by Western Project of China Scholarship Council. File No: 20120815030.
} 
vocabulary learning is a byproduct of activities which are not explicitly directed to vocabulary learning, but to reading comprehension, listening or communication.

\section{B. Definition of Glossing}

Glossing is the explanation of the meanings of unknown or unfamiliar words, which functions as a teaching aid (Roby, 1999). It is one form of input modification, which serves as a pedagogical intervention in which language teachers manipulate a target form to help the learners acquire it. Likewise, glossing can be used as modified input to facilitate vocabulary learning because it helps learners cope with insufficient contextual clues by providing additional information such as definition or synonyms of new words in texts. Nation (2001, p.174) stated that "a gloss is a brief definition or synonym, either in L1 or L2, which is provided with the text", and it is one of the instructional technique for the elaboration of the input through reading. According to online Webster's dictionary, glosses are defined as "an interpretation, consisting of one or more words, interlinear or marginal; an explanatory note or comment; a running commentary".

Input modification acts as an important field in second language research. There are various ways of modifying the textual input, and the motivation is based on the assumption that textual input must be comprehensible to facilitate vocabulary gain. Thus glossing is generally utilized to modify the original texts and to increase the comprehensibility of reading materials. Moreover, such increased comprehensibility has been shown to promote language acquisition (Hulstijin, 1996; Pulido, 2004). In this study, gloss types involved are Chinese translations of unknown English words in reading material, presented under the glossing condition of multiple-choice and single-gloss format.

\section{Glossing in Incidental Vocabulary Acquisition}

Incidental vocabulary acquisition is generally regarded as an important way for learners to enlarge vocabulary. And reading is an essential source for incidental vocabulary acquisition to occur. However, incidental vocabulary acquisition is far from perfect. Incidental learning of words via guessing from context has its own limitations. Huckin and Coady (1999, p.189) expressed the similar view that "Guessing is effective only when the context is well understood and almost all of the surrounding words in the text are known, which requires good textual clues and substantial prior vocabulary knowledge on the part of the learner". Use of glosses, however, offers a possible option of dealing with the problems. Thus providing glossing in texts is an effective way for EFL learners to acquire vocabulary incidentally considering the fact that sometimes it's difficult for them to figure out the new words accurately. For example, single glosses eliminate the risk of making wrong inferences by providing definite meanings of new words. Multiple-choice glosses direct and channel the inferring process by presenting options from which learners choose the meaning in accordance with the context. Generally, the two types of glosses are considered to be appropriate for learners with less problem-solving skills.

In spite of a long history of glossing providing in reading materials, glossing has not been largely explored until late in the 20th century. To facilitate reading and understanding, L2 texts are often augmented with glosses that have been shown to have a positive effect on vocabulary learning (Nation, 2001). Yoshii (2006) examined the effects of L1 and L2 glosses on incidental vocabulary learning in a multimedia environment. In that study the findings showed that both L1 glosses and L2 glosses were positive for incidental vocabulary learning. The differences between L1 and L2 glosses, however, did not reach statistical significance in the vocabulary definition supply and vocabulary recognition tests. Rott (2005) assessed the effectiveness of gloss types, i.e., multiple-choice glosses and single-translation glosses on incidental vocabulary gain and retention. The participants were 10 English learners of Germen who were required to read a text with either multiple-choice glosses or single-translation glosses. The findings illustrated that the multiple-choice gloss group outperformed significantly the single-translation group in retaining word knowledge after four weeks of treatment. The small sample in his study and the think-aloud method used in the reading process, however, might affect the research results. In general, there is a mixed result as to the superiority of multiple-choice glosses over single glosses and it's hardly to get a consensus view.

\section{RESEARCH DESIGN}

\section{A. Research Questions}

This study tends to investigate the effects of different types of glosses on Chinese EFL learners' incidental vocabulary acquisition. Thus, it is to address the following questions:

(1) Which gloss type will be more effective for incidental vocabulary acquisition, multiple-choice or single glosses?

(2) During the process of incidental vocabulary learning, which gloss type is more conductive to vocabulary production?

\section{B. Method}

\section{Participants}

The participants were 120 college undergraduates from 4 intact classes from School of Foreign Languages, Sichuan University of Arts and Science. According to their reading comprehension scores in CET6 (College English Test-Band 6, one of the most authoritative tests in China), the full score of which is 35 points, those students who scored 25-30 were 
chosen as the subjects of this experiment. Eventually 75 of them were selected from 120, and all the subjects were considered as at the same English proficiency level in reading comprehension. Then they were equally and randomly divided into three groups: the single gloss group, the multiple-choice gloss group, and the control group (no gloss group). Each group has 25 subjects respectively.

\section{Materials}

The reading text from the American magazine Time was adapted to the participants' English level. It's readablility was 8th-grade level, measured by the Flesch-Kincaid readability scale. The length of it was a 367-word long with 8 new words. That's to say, the coverage of unknown word rate is about 2.2\%. Nation (1990) and Laufer (1997) put forward that mastery of $95 \%$ known words in a text is necessary for general text comprehension, and Carver (1994) found that difficult reading materials contained around $2 \%$ or more unknown words and materials for pleasant reading contained around $1 \%$ unknown words. According to these findings, this reading material was a perfect one for this study.

3. Procedure

The experiment lasted about five weeks. In the first week, the participants were identified according to their scores in reading comprehension in College English Test Band-6. Eventually 75 participants were chosen from the total number of 120. In the second week, a pilot study was carried out to identify unknown words and target words. In the third week, a reading comprehension task was conducted in class, which was followed by the immediate vocabulary tests. In the fifth week, the delayed vocabulary tests were administered.

In the immediate tests, the three groups were instructed to read the chosen article in class respectively on the same day. The 8 unknown words were glossed under one of the three conditions: single glosses, multiple-choice glosses and no glosses. To ensure that all the subjects were intent on passage comprehension, not on intentional vocabulary learning, they were instructed to recall the article in Chinese on another blank paper in about 200 words after reading. Eventually the three groups took the immediate vocabulary test as well as making sentence with each target word.

Two weeks later the delayed vocabulary tests were administered. The format of it was identical to that of the immediate vocabulary tests.

4. Scoring and data analysis

The vocabulary test was in the form of target-word translation. The subjects were required to provide the Chinese meanings of the 8 target words. A correct answer was assigned 1 point, and a wrong answer was marked 0 point. Besides, a partially correct answer was given 0.5 point. Then the vocabulary test was scored 8 points in total. The same scoring system was applied in the immediate and delayed vocabulary test except that in sentence making. Based on Parabakht and Wesche's Vocabulary Knowledge Scale (Wesche, 1996), the 0-3 point scale was adopted in sentence-making. 0 represents no response at all or the word is used totally inappropriately; 1 represents semantic appropriateness, but with some serious mistakes in part of speech or grammar; 2 represents appropriate semantics, but some minor mistakes in grammar or spelling; 3 represented semantic appropriateness as well as grammatical accuracy.

\section{RESULTS AND DISCUSSION}

\section{A. Results of the Vocabulary Test}

Table 3.1 shows the mean scores of the single gloss group, the multiple-choice gloss group and the control group (no gloss) obtained in the immediate and delayed vocabulary tests.

TABLE 3.1

TABLE 3.1
MEAN SCORES OF EACH GROUP OBTAINED IN THE VOCABULARY TESTS
\begin{tabular}{|l|l|l|l|}
\hline & S group & M group & C group \\
\hline Immediate vocabulary Test & 2.28 & 2.86 & .80 \\
\hline Delayed Vocabulary Test & 1.26 & 1.89 & .34 \\
\hline Note: $\mathrm{S}=$ Single gloss M = Multiple-choice gloss & $\mathrm{C}=$ Control group
\end{tabular}

In the immediate vocabulary test, the mean score of the single gloss group was 2.28 , only second to 2.86 of the multiple-choice gloss group. And the mean score of the control group was .84, the lowest among the three groups. In the delayed vocabulary test, the scores of the single gloss group, multiple-choice gloss group and control group were 1.26, 1.89 and .34 respectively.

Independent-samples $t$-tests were used to explore whether multiple-choice glosses and single glosses were significantly different in enhancing lexical gain. The results are shown in Table 3.2.

TABLE 3.2

INDEPENDENT-SAMPLES T-TESTS ON THE MEAN SCORES BETWEEN THE SINGLE AND MULTI-CHOICE GLOSS GROUP IN THE IMMEDIATE AND DELAYED VOCABULARY TESTS

\begin{tabular}{|l|l|l|l|l|l|}
\hline & Df & T & Mean Difference & Std. Error Difference & Sig. \\
\hline Immediate Vocabulary Test & 49 & 2.44 & -.62 & .25 & $.015 *$ \\
\hline Delayed Vocabulary Test & 49 & 2.39 & -.56 & .23 & $.023 *$ \\
\hline
\end{tabular}

According to table 3.2, there was a significant difference of mean scores between the single gloss group and the multiple-choice gloss group in the immediate vocabulary test $(\mathrm{t}=-2.44, \mathrm{p}=.015<.05)$. Meanwhile, it appeared that there 
was a significant difference of mean scores between the single gloss group and the multiple-choice gloss group in the delayed vocabulary test as well $(\mathrm{t}=-2.39, \mathrm{p}=.023<.05)$. That's to say, multiple-choice glosses generated better learning effects than single glosses on incidental vocabulary learning in both immediate and delayed tests.

\section{B. Results of the Vocabulary Production Test}

Lexical knowledge is construed as a continuum consisting of several levels and dimensions of knowledge starting from superficial familiarity with a word to ending with the ability of using the word correctly in free production (Nation 2001; Laufer \& Goldstein, 2004). Receptive knowledge is usually defined as the word knowledge needed to understand a word in reading or listening, while productive vocabulary knowledge involves expressing a meaning through speaking or writing and retrieving and producing the appropriate spoken or written word form (Nation, 2001).

TABLE 3.3

MEAN SCORES OF EACH GROUP OBTAINED IN THE VOCABULARY PRODUCTION TESTS

\begin{tabular}{|l|l|l|l|}
\hline & S group & M group & C group \\
\hline production test $\left(3^{\text {rd }}\right.$ week $)$ & 10.60 & 14.46 & 4.02 \\
\hline production test $\left(5^{\text {th }}\right.$ week $)$ & 6.42 & 8.20 & 3.42 \\
\hline
\end{tabular}

In order to determine which gloss type was more conductive to vocabulary production, both multi-choice and single gloss groups' production vocabulary gain were compared. As Table 3.3 shows, in the immediate tests ( $3^{\text {rd }}$ week), the mean gains for the two groups are 14.46 and 10.60 receptively, and 8.20 and 6.42 in the delayed tests $\left(5^{\text {th }}\right.$ week). As indicated in Table 3.4, the means of the two groups is significantly different in the immediate tests $(\mathrm{t}=5.37, \mathrm{p}=.000<.05)$ and in the delayed tests $(\mathrm{t}=2.50, \mathrm{p}=.019<.05)$.

TABLE 3.4

INDEPENDENT-SAMPLES T-TESTS ON THE MEAN SCORES BETWEEN THE SINGLE AND MULTI-CHOICE GLOSS GROUP IN THE VOCABULARY PRODUCTION TESTS

\begin{tabular}{|l|l|l|l|l|l|}
\hline Gross type & number & M & SD & t & Sig (2-tailed) \\
\hline$\left(3^{\text {nd }}\right.$ week $)$ & 25 & 10.60 & 3.92 & 5.37 & $.000^{*}$ \\
S group & 25 & 14.46 & 4.83 & & \\
M group & & & & & \\
\hline$\left(5^{\text {th }}\right.$ week $)$ & 25 & 6.42 & 5.08 & 2.50 & $.019^{*}$ \\
S group & 25 & 8.20 & 5.01 & & \\
M group & \multicolumn{5}{|c|}{ Note: ${ }^{*} \mathrm{p}<.05$} \\
\hline
\end{tabular}

\section{Discussion}

The goal of this study is to explore if glossing promotes Chinese EFL learners' incidental vocabulary acquisition. If it does, which gloss type will be more effective for incidental vocabulary acquisition, multiple-choice or single glosses? Meanwhile, it aims to investigate the effects of gloss types on vocabulary production in this study. Results showed that glossing did facilitate incidental vocabulary acquisition through reading, and multiple-choice glosses were superior to single glosses in the immediate and delayed vocabulary tests. Compared with single gloss type, multi-choice gloss facilitated the development of productive vocabulary significantly.

The findings can be explained in terms of the Involvement Load Hypothesis (Laufer \& Hulstijn, 2001). It elaborates on the incidental vocabulary acquisition from the perspective of cognitive psychology. According to it, the gain and retention of new words acquired incidentally depends on the degree of involvement load invested in processing these words. In other words, activities with higher involvement loads yield better vocabulary retention effects. That's to say, the larger the involvement load is, the better the incidental vocabulary learning will be. The involvement load can be measured by three factors: need, search and evaluation. The opportunity for search, which refers to "the attempt to find the meaning of an unknown L2 word or trying to find the L2 word form expressing a concept" (Laufer \& Hulstijn, 2001, p.14), seems to be clearly different in the three groups in the present study. Evaluation entails a "comparison of a given word with other words, a specific meaning of a word with its other meanings, or combining the word with other words in order to assess whether a word does or does not fit its context" (Laufer \& Hulstijn, 2001, p.14). Apparently the levels of evaluation also appear to be different under the three glossing condition. Each factor has it's degree of prominence, i.e., moderate or strong. In this study, multiple-choice glosses induced an involvement load index of 2 (+need, -search, +evaluation), single glosses generated an involvement index of 1 (+need, -search, -evaluation), while no gloss generated 0 (-need, -search, -evaluation). Thus the unknown words with multi-choice gloss, definitely, were processed more deeply with greater involvement load. Subsequently, better vocabulary retention and prouction was achieved in multi-choice gloss group compared with the other groups.

The finding in the present study as to multiple-choice glossing is consistent with that gained by Hulstijn (1996), Nagata (1999), Duan \& Yan (2004) and Rott (2005). There is, however, something different from Watanabe's (1997) findings. In Watanabe's (1997) study, no statistically significant difference was reached between the single gloss and the multiple-choice gloss conditions. The different findings might be explained by the design of distractors in the multiple-choice glosses in his experiment. In Watanabe's study, the subjects were provided with a partially correct 
meaning of the target word as a distractor. This study shows evidence for the efficacy of the Involvement Load Hypothesis from the perspective of glossing. This Hypothesis provides a way for teachers to channel the incidental learning process and to predict which word is more likely to be grasped incidentally by learners. According to the involvement loads specified by the hypothesis, some activities can be designed to facilitate incidental vocabulary acquisition, for example, teachers can develop some after-reading activities with higher involvement loads to foster the learning of the important words.

\section{CONCLUSION}

In China, students are faced with the problem of how to enlarge vocabulary efficiently. Glossing new words in reading materials can ease learners' burden of dictionary use, help them read smoothly without much interference of reading process and prevent possible wrong inference or guessing. In order to acquire new words incidentally, first of all, EFL learners need to develop a form-meaning connection. Glossing, which serve as direct word form-meaning connection, is favored by most pedagogical material developers and practitioners as well. Glossing in this study has been proved to lead to higher vocabulary gain and retention than no glosses. Meanwhile the superiority of multiple-choice glosses over single glosses was illustrated as well in the present study. It implies that pedagogical material developers can apply multiple-choice glosses in reading materials in addition to the conventional single glosses. Thus, EFL learners might comprehend new words involving more mental loads and hence gain more knowledge about new words subsequently.

Although carefully designed, the present study is still prone to drawbacks and shortcomings like any other studies. A small sample in this study might affect the validity of the results. Future studies using a larger sample of Chinese EFL Learners with different proficiency levels are expected to provide more reliable results. Besides, this study only examined the effects of texts with gloss types on incidental vocabulary learning, and vocabulary gain was only examined in terms of semantic feature under the glossing condition. Vocabulary knowledge, however, consists of different aspects, such as morphological, orthographic and syntactic features, then it is necessary to explore whether the results of this study can be applied when the other factors of vocabulary knowledge are involved. Hopefully it will attract more attention from EFL teachers, reading material developers and researchers as well.

\section{ACKNOWLEDGEMENT}

I would like to thank my friends Robert Gerber who encouraged me in writing. I would also like to thank Nancy Lee and Jay Landis who are reviewers for their careful reading and very helpful comments. Last but not least, I appreciate the editors of Theory and Practice in Language Studies for their reading and valuable suggestion.

My greatest debt of gratitude is to my families for their love, support and encouragement they have been giving during this study.

\section{REFERENCES}

[1] Carver, P. (1994). Percentage of unknown vocabulary words in text as a function of the relative difficulty of the text: Implications for instruction. Journal of Reading Behavior 26.4, 413-437.

[2] Duan Shiping \& Yan Chensong (2004). The effect of multiple-choice glossing on L2 incidental vocabulary learning. Foreign Language Teaching and Research 36.3, 213-218.

[3] Huckin, T., \& Coady, J. (1999). Incidental vocabulary acquisition in a second language: A review. Study in Second Language Acquisition 21, 181-193.

[4] Laufer, B. (1997). The lexical plight in second language reading: Words you don't know, words you think you know, and words you can't guess. In J. Coady \& T. Huckin (Eds.), Second language vocabulary acquisition: A rationale for pedagogy. Shanghai: Shanghai Foreign Language Education Press, 20-30.

[5] Laufer, B. (2001). What's in a word that makes in hard or easy? Intralexicalfactors affecting the difficulty of vocabulary acquisition. In N. Sc:hmitt \& M. McCarthy, (eds.). Vocabulary Description acquisition and Pedagogy. Cambridge: Cambridge Universitv Press. 259-286.

[6] Laufer, B. \& Goldstein, Z. (2004). Testing vocabulary knowledge: Size, strength, and computer adaptiveness. Language Learning 54, 399-436.

[7] Laufer, B., \& Hulstijn, J. (2001). Incidental vocabulary acquisition in a second language: The construct of task-induced involvement. Applied Linguistics 22, 1-26.

[8] Makoto, Y. (2006). L1 and L2 Glosses: Their Effects on Incidental Vocabulary Learning. Language Learning and Technology 10, 85-101.

[9] Mondria, J. A. (2003). The effects of inferring, verifying, and memorizing on the retention of L2 word meanings: An experimental comparison of the "meaning-inferred method" and the "meaning-given method." Studies in Second Language Acquisition 25.4, 473-499.

[10] Nagata, N. (1999). The effectiveness of computer assisted interactive glosses. Foreign Language Annals 32.4, 469-479.

[11] Nation, P. (1990). Teaching and Learning Vocabulary. New York: Newbury House.

[12] Nation, P. (2001). Learning Vocabulary in Another Language. Cambridge: Cambridge University Press.

[13] Pulido, D. (2004). Modeling the role of second language proficiency and top familiarity in second language incidental vocabulary acquisition through reading. Language Learning 2, 233-284. 
[14] Roby, W. (1999). What's in a gloss? Language Learning and Technology 2.2, 94-101.

[15] Rott, S. (2005). Processing glosses: A qualitative exploration of how form-meaning connections are established and strengthened. Reading in a Foreign Language 17.2, 95-124.

[16] Watanabe, Y. (1997). Input, intake and retention: Effects of increased processing on incidental learning of foreign language vocabulary. Studies of Second Language Acquisition 19, 287-308.

[17] Wesche, M. \& Paribakht, S. (1996). Assessing second language vocabulary knowledge: Depth versus breadth. The Canadian Modern Language Review 53, 13-41.

[18] Yoshii, M. (2006). L1 and L2 glosses: Their effects on incidental vocabulary learning. Language Learning and Technology 10.3, 85-101.

Xiaoli Gan was born in Sichuan, China in 1977. She is a lecturer in the School of Foreign Languages, Sichuan University of Arts and Science, Sichaun, China. Currently she is studying as a visiting scholar in Eastern Mennonite University, VA, U.S. Her re search interests include Second Language Acquisition and Foreign Language Teaching. 